Marquette University

e-Publications@Marquette

$1-1-2017$

\title{
Authors' Response to Commentary by Drs Sueki and Achhnani on the Article, "Does Exercise Decrease Pain via Conditioned Pain Modulation in Adolescents?"
}

Stacy Stolzman

Marquette University

Marie K. Hoeger Bement

Marquette University, mariehoeger.bement@marquette.edu

Accepted version. Pediatric Physical Therapy, Vol. 29, No. 1 (January 2017): 102-103. DOI. (C) 2017 Wolters Kluwer Health, Inc. and Section on Pediatrics of the American Physical Therapy Association. Used with permission. 


\title{
Authors' Response to Commentary by Drs Sueki and Achhnani on the Article, "Does Exercise Decrease Pain via Conditioned Pain Modulation in Adolescents?”
}

\author{
Stacy Stolzman \\ Department of Physical Therapy, Marquette University, \\ Milwaukee, Wisconsin \\ Marie Hoeger Bement \\ Department of Physical Therapy, Marquette University, \\ Milwaukee, Wisconsin
}

\section{Author Information}

Clinical \& Translational Rehabilitation Health Sciences PhD Program, Department of Physical Therapy Marquette University, Milwaukee, Wisconsin The authors declare no conflicts of interest.

We thank Drs Sueki and Achhnani for their commentary on our article: Does Exercise Decrease Pain via Conditioned Pain Modulation in Adolescents? ${ }^{1}$ We appreciate the opportunity to respond to their comments regarding the application of our study. First, we agree that adolescents may have a less developed pain vernacular, which is why we selected pain Pediatric Physical Therapy, Vol 29, No. 1 (January 2017): pg. 102-103. DOI. This article is ( Wolters Kluwer Health, Inc. and Section on Pediatrics of the American Physical Therapy Association and permission has been granted for this version to appear in e-Publications@Marquette. Wolters Kluwer Health, Inc. and Section on Pediatrics of the American Physical Therapy Association does not grant permission for this article to be further copied/distributed or hosted elsewhere without the express permission from Wolters Kluwer Health, Inc. and Section on Pediatrics of the American Physical Therapy Association. 
NOT THE PUBLISHED VERSION; this is the author's final, peer-reviewed manuscript. The published version may be accessed by following the link in the citation at the bottom of the page.

assessments (pressure pain thresholds, 11-point numeric pain rating scale, and McGill Pain Questionnaire) that were age appropriate and validated for this population. ${ }^{2-5}$ As for consistent pain responses, we have previously shown that adolescents report similar pressure pain thresholds before and after 20 minutes of quiet rest. 6,7

In relation to assessing pain in adolescents and whether pain may actually be a measure of exertion, we do not believe that pain reported during the treadmill (TM) activity was a measure of exertion because ratings of perceived exertion (RPE) was part of the criteria for exercise termination. Despite all the adolescents meeting the American College of Sports Medicine criteria (eg, RPE > 8),7 there was a wide range of pain responses; 9 adolescents reported no pain and 14 adolescents reported severe pain during the treadmill test. Similarly, we agree that psychological factors like "fear on treadmill" could impact the conditioned pain modulation (CPM) response; however, we do not believe that this occurred in our protocol because CPM and TM exercise were conducted during separate randomized sessions. 6,7

We agree that the relationship between CPM (ie, pain inhibits pain) and exercise-induced hypoalgesia (EIH) is weak and does not provide evidence that CPM is a mechanism for pain relief following exercise. Furthermore, pain reported during exercise did not contribute to the pain relief reported following exercise. For example, adolescents were able to exercise to exhaustion and experience pain relief postexercise despite some reporting no pain whereas others reporting severe pain during the TM protocol. A recent study in people with knee osteoarthritis has shown that those participants with normal CPM reported EIH following exercise that was performed with minimal pain $(<3 / 10)$, whereas those participants with abnormal CPM reported hyperalgesia (ie, decrease in pressure pain thresholds) following the exercise protocol. ${ }^{8}$ Thus, while it is not known whether CPM is a mechanism for $\mathrm{EIH}$, there is evidence for the assessment of CPM in the clinic as it may help to establish a patient's response to a single exercise session. ${ }^{9}$

In their commentary, Sueki et al concluded that "in patients with persistent pain, clinicians should exercise below pain levels and avoid high-intensity exercise." ${ }^{11}$ We are hesitant to translate our 
findings to chronic pain populations because the adolescents in our study did not have chronic pain. We agree that exercise dose for pain relief may be different for healthy individuals compared with individuals with chronic pain. Unfortunately, very little research is available regarding the optimal dose of exercise to relieve pain. A meta-analysis assessing pain responses following a single exercise session concluded that effects sizes were highly variable for individuals with chronic pain; although moderate/high-intensity exercise may exacerbate pain for individuals with widespread chronic pain. ${ }^{10}$ Similarly, we have shown that women with fibromyalgia experience variability in their pain response (ie, increase, decrease, and no change in pain) following isometric contractions held to exhaustion. ${ }^{11}$ In the current adolescent study, pain relief was assessed following a single exercise session only. This is an important distinction because pain that occurs with exercise initiation may not reflect pain relief that occurs with exercise training. ${ }^{12}$

When starting an exercise program for pain management or other rehabilitation exercise protocols, clients frequently report pain with exercise. Consequently, pain with exercise may not be avoided and should be addressed by physical therapists. Our expertise in nonpharmacological pain management is a vital component for overall health and wellness, in part due to the decreasing usage of opioids. For example, pain with exercise may be addressed through the incorporation of modalities (transcutaneous electrical nerve stimulation [TENS] and thermal agents), CPM (ice water bath and noxious TENS), and patient education (hurt vs harm). Finally, for individuals with a regional pain condition, exercise is an excellent option because of its systemic effects; exercising a distal muscle can produce $\mathrm{EIH}$ at the painful muscle. ${ }^{10}$ We look forward to continuing this discussion and exploring the best way to use exercise and CPM in pediatric physical therapy.

\section{References}

\section{${ }^{1}$ Sueki D, Achhnani H. Commentary on "Does Exercise Decrease Pain via Conditioned Pain Modulation in Adolescents?" Pediatric Physical Therapy. Winter 2016;28(4):474.}

${ }^{2}$ Birnie KA, Caes L, Wilson AC, Williams SE, Chambers CT. A practical guide and perspectives on the use of experimental pain modalities with children and adolescents. Pain Manag. 2014;4(2):97-111. 
NOT THE PUBLISHED VERSION; this is the author's final, peer-reviewed manuscript. The published version may be accessed by following the link in the citation at the bottom of the page.

${ }^{3}$ Drendel AL, Brousseau DC, Gorelick MH. Pain assessment for pediatric patients in the emergency department. Pediatrics. $2006 ; 117(5): 1511-1518$.

${ }^{4}$ Cohen LL, Lemanek K, Blount RL, et al. Evidence-based assessment of pediatric pain. J Pediatr Psychol. 2008;33(9):939-955.

${ }^{5}$ Melzack R. The McGill pain questionnaire: major properties and scoring methods. Pain. 1975;1(3):277-299.

${ }^{6}$ Stolzman S, Hoeger Bement M. Lean mass predicts conditioned pain modulation in adolescents across weight status. Eur J Pain. $2016 ; 20(6): 967-976$.

${ }^{7}$ Stolzman S, Danduran M, Hunter SK, Bement MH. Pain response after maximal aerobic exercise in adolescents across weight status. Med Sci Sports Exerc. 2015;47(11):2431-2440.

${ }^{8}$ Fingleton C, Smart K, Doody C. Exercise-induced hypoalgesia in people with knee osteoarthritis with normal and abnormal conditioned pain modulation [published online ahead of print August 11, 2016]. Clin J Pain. doi:10.1097/AJP.0000000000000418.

${ }^{9}$ Lemley KJ, Hunter SK, Bement MK. Conditioned pain modulation predicts exercise-induced hypoalgesia in healthy adults. Med Sci Sports Exerc. 2015;47(1):176-184.

${ }^{10}$ Naugle KM, Fillingim RB, Riley JL 3rd. A meta-analytic review of the hypoalgesic effects of exercise. J Pain. 2012;13(12):1139-1150.

${ }^{11}$ Hoeger Bement MK, Weyer A, Hartley S, Drewek B, Harkins AL, Hunter SK. Pain perception after isometric exercise in women with fibromyalgia. Arch Phys Med Rehabil. 2011;92(1):89-95.

${ }^{12}$ Andersen LL, Kjaer M, Sogaard K, Hansen L, Kryger AI, Sjogaard G. Effect of two contrasting types of physical exercise on chronic neck muscle pain. Arthritis Rheum. 2008;59(1):84-91.

Pediatric Physical Therapy, Vol 29, No. 1 (January 2017): pg. 102-103. DOI. This article is (C) Wolters Kluwer Health, Inc. and Section on Pediatrics of the American Physical Therapy Association and permission has been granted for this version to appear in e-Publications@Marquette. Wolters Kluwer Health, Inc. and Section on Pediatrics of the American Physical Therapy Association does not grant permission for this article to be further copied/distributed or hosted elsewhere without the express permission from Wolters Kluwer Health, Inc. and Section on Pediatrics of the American Physical Therapy Association. 